\title{
BIOLOGICAL AND ANALYTICAL STUDIES OF PERITONEAL DIALYSIS SOLUTIONS
}

\author{
N. HUDZ ${ }^{1 凶}$, L. KOBYLINSKA ${ }^{1}$, N. DMYTRUKHA ${ }^{2}$, \\ R. KORYTNIUK ${ }^{3}$, P. P. WIECZOREK ${ }^{4}$ \\ ${ }^{1}$ Danylo Halytsky Lviv National Medical University, Ukraine; \\ 凶e-mail: natali_gudz@ukr.net; \\ ${ }^{2} S I$ "Institute for Occupational Health of National Academy \\ of Medical Sciences of Ukraine”, Kyiv; \\ ${ }^{3}$ Shupyk National Medical Academy of Postgraduate Education, Kyiv, Ukraine; \\ ${ }^{4}$ University of Opole, Poland
}

The purpose of our work was to conduct biological and analytical studies of the peritoneal dialysis (PD) solutions containing glucose and sodium lactate and establish correlations between cell viability of the Vero cell line and values of analytical indexes of the tested solutions. The results of this study confirm the cytotoxicity of the PD solutions even compared with the isotonic solution of sodium chloride, which may be due to the low $\mathrm{pH}$ of the solutions, presence of glucose degradation products (GDPs) and high osmolarity of the solutions, and unphysiological concentrations of glucose and sodium lactate. However, it is not yet known what factors or their combination and to what extent cause the cytotoxicity of PD solutions. In the neutral red $(N R)$ test the weak, almost middle ( $r=-0.496$ and 0.498 , respectively) and unexpected correlations were found between reduced viability of monkey kidney cells and increased $\mathrm{pH}$ of the PD solutions and between increased cell viability and increased absorbance at $228 \mathrm{~nm}$ of the tested PD solutions. These two correlations can be explained by a strong correlation $(r=-0.948)$ between a decrease in $\mathrm{pH}$ and an increase in the solution absorbance at $228 \mathrm{~nm}$. The opposite effect was observed in the MTT test. The weak, but expected correlations ( $r=0.32$ and -0.202 , respectively) were found between increased cell viability and increased $p H$ in the PD solutions and between decreased cell viability and increased absorbance at $228 \mathrm{~nm}$ of the tested PD solutions. The middle and weak correlations ( $r=0.56$ and 0.29 , respectively) were detected between increased cell viability and increased lactate concentration in the NR test and MTT test. The data of these correlations can be partially explained by the fact that a correlation with a coefficient $r=-0.34$ was found between decreased $p H$ in the solutions and increased lactate concentration. The very weak correlations (0.138 and 0.196, respectively) were found between increased cell viability and increased glucose concentration in the NR test and MTT test. These experimental data indicate that $\mathrm{pH}$ is the dominating factor, which determines almost all of the established correlations. However, the character of the correlations is quite different: the higher the $p H$, the greater was the cell viability in the MTT test, and conversely, the higher the $\mathrm{pH}$, the lower was the cell viability in the NR test. Secondly, the unexpected correlation coefficient was determined as -0.473 between decreased cell viability in the MTT test and increased cell viability in the NR test. Moreover, this phenomenon indicates that the mitochondrial enzyme succinate dehydrogenase is more vulnerable to the action of PD solutions than membrane permeability. Finally, we conclude that the NR test is not suitable for comparative studies of PD solutions which differ in $\mathrm{pH}$, as it is $\mathrm{pH}$ dependent and does not enable the comparison of plausible cell viability.

Ke y w o rd s: solutions for peritoneal dialysis, cell viability, kidney cells (Vero line), neutral red, MTT.

W orldwide, there is an increasing number of patients affected by chronic kidney disease (CKD). The progressive nature of CKD and the subsequent end stage renal disease
(ESRD) are putting a substantial burden on global health-care resources. It had been estimated that 2.3 million patients globally would have ESRD by the end of 2008, and that number already increased to

(C) 2018 Hudz N. et al. This is an open-access article distributed under the terms of the Creative Commons Attribution License, which permits unrestricted use, distribution, and reproduction in any medium, provided the original author and source are credited. 
3.37 million by the end of 2014. This rise represents a $46.5 \%$ increase in 6 years [1, 2]. Accordingly, the number of patients undergoing renal replacement therapy (RRT) increased from 1.77 million to 2.67 million since 2008 through the end of 2014. By 2030, the worldwide use of RRT is projected to more than double to 5.439 million (range of 3.899 to 7.640 million) people. In general, with the increasing population of ESRD patients, the incidence of all modalities of RRT is growing, with an estimate of 6 to $7 \%$ in hemodialysis (HD), 8\% in peritoneal dialysis (PD), and 4 to $5 \%$ in renal transplants [2]. PD has been reported as one of the convenient, safe and efficient modalities of RRT during the last 50 years. Treatment with PD allows RRT to be performed at home and thus maintains a better integration of the patient into normal social life, even though it imposes a major burden on families [2, 3]. Other advantages of PD are lower hemodynamic stress, longer preservation of residual renal function, and potential cost savings [1, 2]. Approximately $10 \%$ of the dialysis population is treated with PD [2]. The extent of PD use varies in different countries. For example, in Hong Kong approximately $76 \%$ of all RRT patients were receiving PD at the end of 2014 [2]. In China, recent annual growth of patients on PD exceeded 20\% (from 37942 patients in 2012 to 55373 in 2014) $[1,2]$. In Ukraine, the number of patients undergoing PD has also increased from 552 to 966 since 2009 through the end of 2013 [4]. However, PD solutions used in Ukraine come from abroad. Hence, domestic manufacture of PD solutions is one of the possible determinants for reducing the burden on health-care resources of the country.

A PD procedure uses sterile solutions of a special composition with a large volume in a total daily amount of 8-40 liters. Solutions containing glucose and sodium lactate are most frequently used [2, 3, 5-8]. Currently, the main way of ensuring the sterility of PD solutions is thermal sterilization [3, 5, 8, 9]. Glucose degradation products (GDPs) are formed during sterilization and following storage, including formaldehyde, 3-deoxyglycosone (3-DG), 3,4-dideoxyglucoson-3-ene (3,4-DGE), 5-hydroxymethylfurfural (5-HMF), methylglyoxal, glyoxal, formaldehyde, acetaldehyde, 2-furaldehyde, low molecular weight acids and other identified and unidentified compounds [3, 5-11]. Currently, according to the British Pharmacopeia only 5-HMF content is regulated in PD solutions containing glucose and sodium lactate: 5-HMF should be not more than $10 \mu \mathrm{g}$ for each $25 \mathrm{mg}$ of glucose. The contents of other GDPs are not regulated [12].

Studies of the last 30 years indicate adverse effects of PD solutions on the peritoneum [3, 5-7, 9, 11, 13, 14]. 3,4-DGE and traditional solutions with high levels of GDPs induce the apoptosis of mesothelial cells by activating caspase [5]. Very high levels of 5-HMF may lead to acute toxicity [11]. Besides, GDPs exert direct nephrotoxic effects on renal tubular cells [5]. Therefore, standard solutions for $\mathrm{PD}$ are considered to be bioincompatible with the peritoneal membrane because of hyperosmolarity, unphysiologically low values of $\mathrm{pH}(5.0-5.5)$, high lactate (35 or $40 \mathrm{mmol} / \mathrm{l}$ ) and glucose contents (1.5$4.25 \%)$. The extent of bioincompatibility depends on the type of an osmolarly active compound (for example, glucose, icodextrin, aminoacids), $\mathrm{pH}$, packaging, and other factors $[2,4,5,13-15]$. In response to the effect of PD solutions, the cellular processes of exchange and regeneration, peroxidation and proliferation are intensified, and the activity of mitochondria and other cytoplasmic organelles increases in mesothelium cells. Constant contact of mesothelium with hyperosmolar PD solutions leads to increased activities of ion pumps on the surface of mesothelium cells, Na/K-ATPase, and alkaline phosphatase, as well as cytoplasmic cytochrome oxidase and glucose-6-phosphatase. Disruption of metabolic processes and biosynthesis of deoxyribonucleic acid in mesothelium cells leads to their degeneration, apoptosis and necrosis [14]. Currently, precise thresholds of toxicity are not yet known for GDPs and advanced glycation end products (AGEs) that are administered to chronically ill patients [11]. GDPs are highly reactive precursors of AGEs and can also generate intracellular reactive oxygen species (ROS) $[11,13]$. AGEs inhibit some growth factors, depress mitosis and stimulate prooxidant factors and possess direct cytotoxic action. ROS promote formation of AGEs and vice versa $[13,14]$. The combination of bioincompatibility of current solutions for PD with chronic inflammation and infection results in abnormal peritoneal repair processes [3, 11, 13].

In the recent two decades, the attention of scientists has been focused on the development of more biocompatible solutions, the use of more advanced sterilization techniques that contribute to less glucose degradation and enrichment of PD solutions with specific active substances $[3,5,7,8]$. An improved biocompatibility was achieved by introducing multichambered bags to reduce generation of GDPs and allow the use of more physiologic buffers 
in order to elevate the $\mathrm{pH}$ of solutions. At the same time, alternative agents were introduced, such as amino acid mixtures and icodextrin. Surprisingly however, according to Cho et al. [5] and Schmitt and Aufricht [3], there are no convincing conclusions about the benefits of solutions with a low content of GDPs for patients [3, 5]. Alternative agents also show bioincompatible properties, for example, icodextrin induces sterile inflammation, and vascular effects are caused by arginine [3]. The beneficial effect of neutral-pH low-GDP PD solutions is only associated with residual renal function (RRF) preservation. Secondly, GDP-depleted PD solutions generated almost as much ROS in human peritoneal mesothelium cells as PD solutions containing a high concentration of GDPs [13]. Partly, bioincompatibility is connected with pharmaceutical manufacture [3]. Therefore, adjusting sterilization processes and elevating the $\mathrm{pH}$ of $\mathrm{PD}$ solutions can be one more approach for improving biocompatibility of these solutions. Currently, the determination of the composition and technology of PD solutions is often carried out in combination with biological studies, namely the study of the viability of cells in the presence of PD solutions $[6-8,15]$. The purpose of our work was to conduct biological and analytical studies of PD solutions containing glucose and sodium lactate, and establish correlations between cell viability and values of analytical indexes of the tested solutions. A review of the scientific literature regarding the existing methods of pharmaceutical development of PD solutions also revealed that there are needs for the elaboration of rapid procedures for determina- tion of glucose degradation products and chloride ions and cell viability of the Vero cell line and for establishing correlations between cell viability and analytical indexes.

\section{Materials and Methods}

The objects of the study were solutions for PD with a content of lactate ions of 35 and $40 \mathrm{mmol} / \mathrm{l}$ and 1.5, 2.5 and $4.25 \%$ of glucose monohydrate in glass and polyvinyl chloride (PVC) containers. The composition of the developed PD solutions is shown in Table 1.

In the present study we applied a chemical test (the argentometric method: a proposed new analytical procedure for determination of chloride ions), spectrophotometry (determination of the content of 3,4-DGE and 5-HMF for the absorbance of the solutions at $228-230 \mathrm{~nm}$ and absorption maximum), potentiometry (measuring $\mathrm{pH}$ of solutions), the MTT test and the neutral red (NR) uptake assay to evaluate the cytotoxic effect of the developed PD solutions using Vero line cells, as well as methods of statistical processing of results [10, 12, 16-19].

Analytical equipment and materials used in this study were the following: pH-150 M (Gomel Plant of Measuring Instruments, Belarus), burettes of I class of accuracy (volume of burette is $25.0 \mathrm{ml}$, division price is $0.05 \mathrm{ml}$, measurement accuracy is $0.03 \mathrm{ml}$ ); and spectrophotometer Optizen POP (Mecasys Co. Ltd., Korea) with a 1-cm quartz cell as used in the range of 200 to $350 \mathrm{~nm}$.

Argentometric method for determination of chloride ions: $10 \mathrm{ml}$ of a PD solution (and $5 \mathrm{ml}$ of

Ta b le 1. Composition of the PD solutions

\begin{tabular}{c|c|c|c|c|c|c|c}
\hline \multirow{2}{*}{ Batch } & \multicolumn{6}{|c|}{ Concentration of ions, $\mathrm{mmol} / \mathrm{l}$} & Glucose monohydrate \\
& \cline { 2 - 5 } & $\mathrm{Na}^{+}$ & $\mathrm{Ca}^{2+}$ & $\mathrm{Mg}^{2+}$ & $\mathrm{Cl}^{-}$ & $\mathrm{CH}_{3} \mathrm{CH}(\mathrm{OH}) \mathrm{COO}^{-}$ & Packaging \\
\hline 0 & 154 & - & - & 154 & - & - & glass \\
$1(10413)$ & 132 & 1.25 & 0.25 & 95 & 40 & 15.0 & $-/ /-$ \\
$2(20413)$ & 132 & 1.25 & 0.25 & 95 & 40 & 42.5 & $-/ /-$ \\
$3(30513)$ & 132 & 1.25 & 0.25 & 95 & 40 & 15.0 & $-/ /-$ \\
$4(40513)$ & 132 & 1.25 & 0.25 & 95 & 40 & 42.5 & $-/ /-$ \\
$5(10415)$ & 132 & 1.25 & 0.25 & 100 & 35 & 15.0 & $-/ /-$ \\
$6(20415)$ & 132 & 1.25 & 0.25 & 100 & 35 & 25.0 & $-/ /-$ \\
$7(30415)$ & 132 & 1.25 & 0.25 & 100 & 35 & 42.5 & $-/ /-$ \\
$8(21116)$ & 132 & 1.25 & 0.25 & 95 & 40 & 42.5 & $\mathrm{PVC}$ \\
$9(10117)$ & 132 & 1.25 & 0.25 & 95 & 40 & 25.0 & $-/ /-$ \\
\hline
\end{tabular}


an isotonic solution of sodium chloride) were titrated with $0.1 \mathrm{M}$ solution of silver nitrate (Argentum, Ukraine) using $0.8 \mathrm{ml}$ of potassium chromate solution (Cherkasy Plant of Reagents, Ukraine) as an indicator $(0.4 \mathrm{ml}$ of potassium chromate solution for the isotonic solution of sodium chloride) to an orange-yellow colour, stirring constantly. The content of chloride ions should be from 95 to $105 \%$ of the stated amount $[12,18]$. Each $\mathrm{ml}$ of $0.1 \mathrm{M}$ silver nitrate is equivalent to $3.545 \mathrm{mg}$ of $\mathrm{Cl}^{-}$. The content of chloride ions $\left(X_{1}\right)$, in $\mathrm{mmol} / \mathrm{l}$, in a PD solution, is calculated according to the following formula:

$$
X_{1}=V_{1} \cdot K \cdot 3.545 \cdot 1000: 10: 35.45=V_{1} \cdot K \cdot 10 .
$$

The content of chloride ions $\left(X_{2}\right)$, in $\mathrm{mmol} / \mathrm{l}$, in an isotonic solution of sodium chloride, is calculated according to the following formula:

$$
X_{2}=V_{2} \cdot K \cdot 3.545 \cdot 1000: 5: 35.45=V_{2} \cdot K \cdot 20,
$$

where: $V_{1}$ and $V_{2}$ are volumes of the $0.1 \mathrm{M}$ solution of silver nitrate used in titration of a tested PD solution and the isotonic solution of sodium chloride, in $\mathrm{ml}$, respectively; $K$ - a correction coefficient to molarity of $0.1 \mathrm{M}$ solution of silver nitrate.

Spectrophotometry. The processes of glucose degradation were estimated by changing the $\mathrm{pH}$ values and the absorbance at $228-230 \mathrm{~nm}$, as well as at maximum absorption in the wavelength range of 273 to $286 \mathrm{~nm}$ before and after sterilization and during storage [10].

pH-Metric measure. The $\mathrm{pH}$ of the PD solutions was measured in the temperature range of 20 to $25{ }^{\circ} \mathrm{C}$. Before measurements, the $\mathrm{pH}$ meters were calibrated using buffer solutions with values of pH 4.01, 6.87 and 9.18.

Cytotoxicity (cell viability) test. The evaluation of the cytotoxic activity of the tested samples was carried out using two cell-based assays: the MTT test and NR uptake (NR test). The NR test is based on the ability of living cells to absorb and accumulate NR dye in lysosomes. Damage of lysosomes leads to a decrease in the accumulation of this dye that is a sign of reduced cell viability. Metabolic activity of cells can be also evaluated by measuring the activity of the mitochondrial enzyme succinate dehydrogenase using the MTT test [16, 17].

The cells of the African monkey kidney (Vero line), obtained from the Institute of Microbiology and Virology of National Academy of Sciences of Ukraine, were the object of the study in vitro. Special equipment was used for cell culture: Class II Biological Safety Cabinet (Thermo Scientific MSC
Advantage, Germany), binocular microscope (MC 300x MET Invert, Austria), Thermo Scientific Revco Ultima II Midi Dry Wall $\mathrm{CO}_{2}$ Incubator (USA), plate rotary centrifuge (Biosan LMC 300, EU), the Tecan's Sunrise absorbance microplate reader (Tecan, Austria), single-dose and multichannel variable-volume dispensers from 1 to $1000 \mu \mathrm{l}$, Goryaev's camera, electronic laboratory scale, household refrigerator with freezer compartment, and potentiometric analyzer with $\mathrm{pH}$ measurement error \pm 0.01 . Cells were cultured in a medium of RPMI 1640 (Sigma, USA) containing $4 \mathrm{mmol} / \mathrm{l}$ L-glutamine, $10 \%$ fetal calf serum (Sigma, USA) and $40 \mu \mathrm{g} / \mathrm{ml}$ gentamicin (Hemofarm AD, Serbia) in a humidified atmosphere at $37^{\circ} \mathrm{C}\left(5 \% \mathrm{CO}_{2}+95 \%\right.$ air $)$. The medium was changed every 2 days. $100 \mu \mathrm{l}$ of a suspension of cells at a density of $1 \times 10^{5}$ cells per $\mathrm{ml}$ were placed into each well of a 96-well plate. The cells were incubated for cell adhesion and monolayer formation in wells during $24 \mathrm{~h}$. Then, $100 \mu \mathrm{l}$ of a PD solution or its appropriate dilution and an isotonic solution of sodium chloride or its appropriate dilution were added in two replicates. $100 \mu 1$ of culture medium were added to the control wells without a tested sample. The plates were incubated in a humidified atmosphere $\left(5 \% \mathrm{CO}_{2}+95 \%\right.$ air) with the thermostat at $37^{\circ} \mathrm{C}$ for 24 hours. Thereafter, the cells were treated with MTT or NR.

Procedure of the MTT test. For preparation of the working MTT solution, $50 \mathrm{mg}$ of MTT (Sigma, USA) were dissolved in $10 \mathrm{ml}$ of Hanks's solution (Sigma, USA). The obtained solution were filtered through a sterile cellulose acetate membrane filter. $10 \mu 1$ of MTT solution were injected into each well. Then incubation were conducted in the thermostat during $3 \mathrm{~h}$. After the incubation, the plates were centrifuged at a rate of $1500 \mathrm{rpm}$ for $5 \mathrm{~min}$, and then supernatant fluid was removed from the wells. $50 \mu \mathrm{l}$ of dimethylsulfoxide (Sigma, USA) were added to each well to dissolve formazan crystals. The plates were kept at room temperature for $30 \mathrm{~min}$, and then the absorbance of the well contents was determined at a wavelength of $540 \mathrm{~nm}$ using Tecan's Sunrise absorbance microplate reader (Tecan, Austria).

Procedure of the NR test. The medium was carefully removed from each well. Cells were washed with $150 \mu 1$ of warm buffer solution. Then $100 \mu \mathrm{l}$ of NR solution were added to each well. Incubation was carried out in a thermostat for $3 \mathrm{~h}$. After the incubation, the NR solution was removed and the wells were washed by adding $150 \mu \mathrm{l}$ of phosphate 
buffer. After removing the buffer, $150 \mu \mathrm{l}$ of extraction solution were added to the well and the plate was gently shaken on the plate shaker for 10 minutes. The absorbance of the well contents was determined at a wavelength of $540 \mathrm{~nm}$ using the Tecan's Sunrise absorbance microplate reader (Tecan, Austria).

The percentage of viability $\left(\%_{\text {viability }}\right)$ was calculated using the formula:

$$
\%_{\text {viability }}=\text { Viability }_{\text {tested }} / \text { Viability } y_{\text {medium }} \times 100 \% \text {, }
$$

where $\%_{\text {viability }}$ - the number of viable cells in $\%$; Viability $_{\text {medium }}$ - the absorbance in the wells with a culture medium; Viability tested $_{-}$- the absorbance in wells with the tested samples.

Correlation Analysis. Achim Buyul and Peter Tsefel's classification was employed to estimate correlation coefficients $(r)$ : up to 0.2 - very weak, up to 0.5 - weak, up to 0.7 - medium, up to 0.9 is high and over 0.9 is very high correlation [19].

\section{Results and Discussion}

Physicochemical tests. Analytical indexes of samples. The results of analytical studies of the laboratory batches of PD solutions are presented in Table 2.

The $\mathrm{pH}$ of the PD solutions was in the range of 5.25 to 5.77 and the actual content of chlorides was in the range of 99.61 to $105 \%$ of the stated amount that meets the requirements of the British Pharmacopeia for PD solutions [12]. 5-HMF content also met the requirements of the British Pharmacopeia for PD solutions. The absorbance of the solutions at $228 \mathrm{~nm}$ ranged from 0.294 to 1.587 indicating the strong fluctuations of the 3,4-DGE content. According to our studies and literature data, 3,4-DGE has an absorption maximum at $228-230 \mathrm{~nm}$, and 5-HMF at 228 and $284 \mathrm{~nm}[10,20]$. Therefore, correlations between cell viability and the $\mathrm{pH}$ and absorbance of the PD solutions at $228 \mathrm{~nm}$ were established. Moreover, UV absorbance and $\mathrm{pH}$ are used as general indicators of degradation [20].

Biological tests. The MTT assay measures cell respiration and is widely used in the in vitro evaluation of the cytotoxic potential of drug products. In this test metabolic activity of cells can be evaluated by measuring the activity of the mitochondrial enzyme succinate dehydrogenase. [16]. The NR uptake assay of viable cells is another one of the most used cytotoxicity test methods. The NR uptake assay may be successfully used in testing most primary cells and cell lines of a diverse origin. This procedure is cheaper and more sensitive than other cytotoxicity tests (tetrazolium salts, enzyme leakage or protein content) [17]. The NR test is based on the ability of viable cells to incorporate and bind the supravital dye NR (a weak cationic dye) in lysosomes. The NR dye penetrates through cell membranes by nonionic passive diffusion and concentrates in the lysosomes. It binds by electrostatic hydrophobic bonds to anionic and/or phosphate groups of the lysosomal matrix. The uptake of NR depends on the capacity of the cell to maintain $\mathrm{pH}$ gradients through the production of ATP. At physiological pH, the dye presents a net charge close to zero, enabling it to penetrate cell membranes. Inside the lysosomes, there is a proton gradient to maintain a $\mathrm{pH}$ lower than that of the cytoplasm. Thus, the dye becomes charged and is retained inside the lysosomes [17]. This in vitro cell-based cytotoxicity assay promises to be a useful, reliable and rapid method for demonstrating activity of medicines or detecting their toxicity. It could be considered as the standard for evaluating innovative and generic PD solutions during pharmaceutical development or existing solutions after improving their composition and manufacture.

It was found that the tested solutions had a negative effect on the membrane permeability and the mitochondrial enzyme succinate dehydrogenase of the kidney cells. The viability of cells in the tested solutions was within the range of 16.32 to $27.25 \%$ and 11.86 to $16.08 \%$ in the NR test and MTT test, respectively, versus $31.79 \pm 0.20 \%$ and $24.69 \pm 0.52 \%$ of viability, respectively, in the presence of an isotonic solution of sodium chloride (Table 2). Compared with the data from the control wells, sample No. 5 showed the largest cytotoxic activity: the percentage of viable cells of the Vero line was $16.32 \pm 1.32 \%$ and $11.86 \pm 0.29 \%$ in the NR and MTT tests, respectively.

Data of the cytotoxic activity of the tested solutions are presented in Table 2. The results of this study confirmed the literature data on the cytotoxicity of PD solutions, even compared with an isotonic sodium chloride solution. However, it is not yet known which factor, analytical index or combination of these factors (indexes) causes cytotoxicity. The relatively insignificant viability of Vero line cells in the presence of an isotonic sodium chloride solution can also be explained, in particular, by the low $\mathrm{pH}$ $(\mathrm{pH}=5.11)$. The tested solutions in a dilution of $3: 1$ showed a slightly less membrane- and mitochondrial-damaging effect. The cell viability was in the 


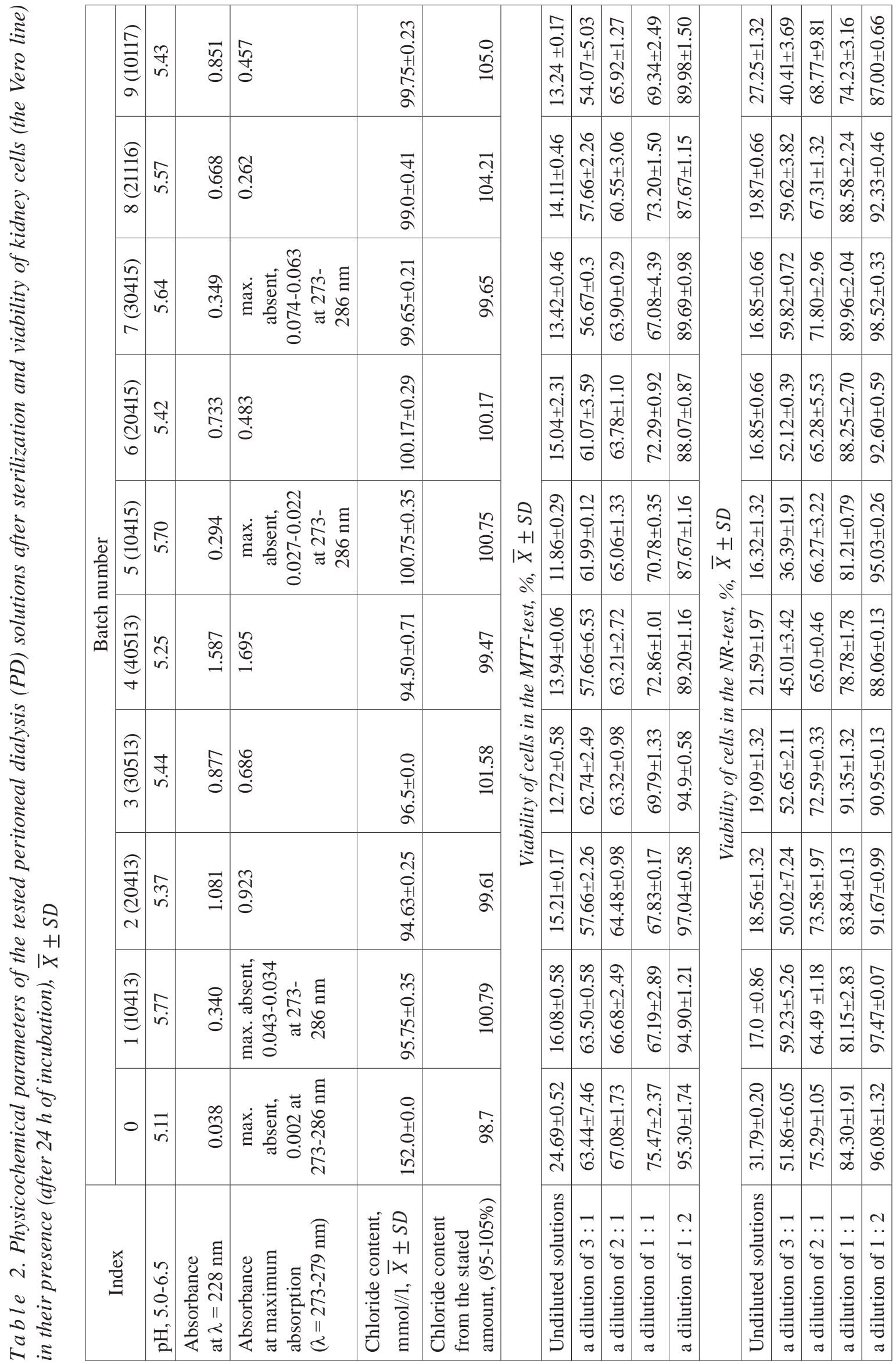


range of 36.39 to $59.82 \%$ in the NR test and 54.07 to $63.50 \%$ in the MTT test. The number of viable cells gradually increased at further dilutions of the tested PD solutions with the medium and it was close to the values in control wells (100\%) at a dilution of $1: 2$. Consequently, the results of cell-based assays suggest that the cytotoxic activity of the tested PD solutions was greatest when the cells were incubated in the presence of the undiluted solutions.

In establishing the correlations, the weak, almost middle but unexpected correlations were found in the NR test between reduced viability of monkey kidney cells and increased $\mathrm{pH}$ of the PD solutions $(r=-0.496)$ and between increased cell viability and increased absorbance at $228 \mathrm{~nm}$ of the PD solutions $(r=0.498)$ (Fig. 1 and 2). The opposite effects were observed in the MTT test. The weak, but expected correlations were found between increased cell viability and increased $\mathrm{pH}$ of the PD solutions $(r=0.32)$ and between decreased cell viability and increased absorbance at $228 \mathrm{~nm}$ of the PD solutions $(r=-0.202)$.

The identity of two correlations $(r=-0.496$ and 0.498 ) in the NR test can be explained by a strong correlation $(r=-0.948)$ between a decrease in $\mathrm{pH}$ and an increase in the solution absorbance at $228 \mathrm{~nm}$, which is elucidated by the following: glucose degradation occurs simultaneously by both cyclization of its molecule and carbon chain fragmentation during sterilization of solutions containing glucose (Fig. 3).

The data presented in Fig. 4 indicate that there was a very weak correlation between the glucose concentration and the cell viability $(r=0.138$ and $0.196)$ in both tests. A significantly stronger corre-

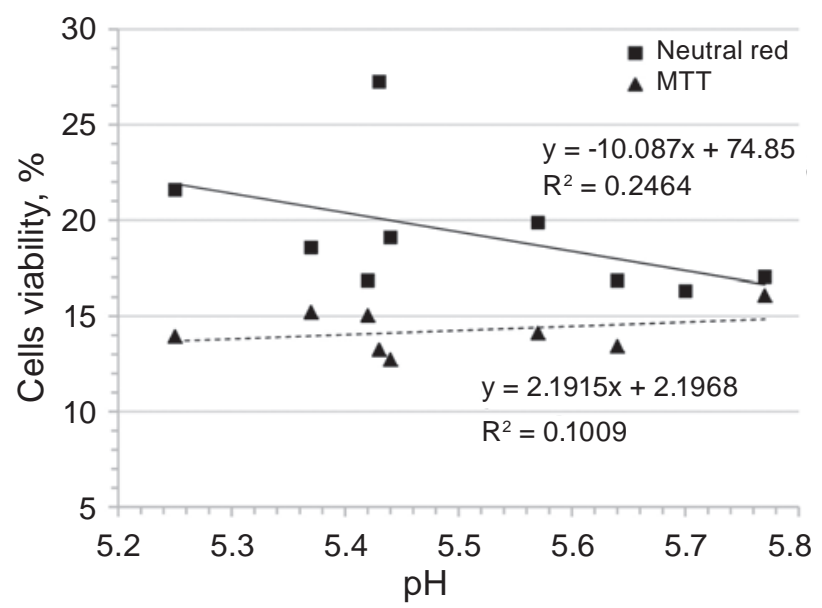

Fig. 1. Comparison of the cell viability for different pHs of the tested PD solutions

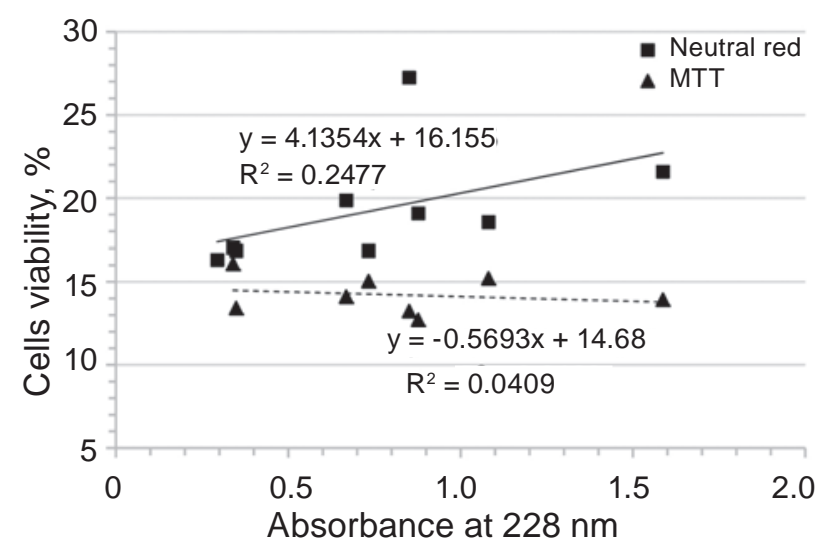

Fig. 2. Comparison of the cell viability for different absorbances at $228 \mathrm{~nm}$ of the tested PD solutions

lation (middle) ( $r=0.56)$ was detected between increased cell viability and increased sodium lactate concentration in the NR test and a weak correlation $(r=0.29)$ was established between increased cell viability and increased sodium lactate concentration in the MTT test (Fig. 5).

The data of this correlation can be partially explained by the fact that a correlation $(r=-0.34)$ was found between decreased $\mathrm{pH}$ of solutions and increased sodium lactate concentration. Comparing cell viability using the two tests, an unusual correlation coefficient of -0.473 was determined between decreased cell viability in the MTT test and increased cell viability in the NR test (Fig. 6). This finding may indicate the different mechanisms of PD solution cytotoxicity, namely a stronger inhibition of mitochondrial activity as measured in the MTT test versus the integrity of membranes and lysosomes as measured in the NR test.

Our study confirms data on cytotoxicity of PD solutions in cell cultures even in comparison with an

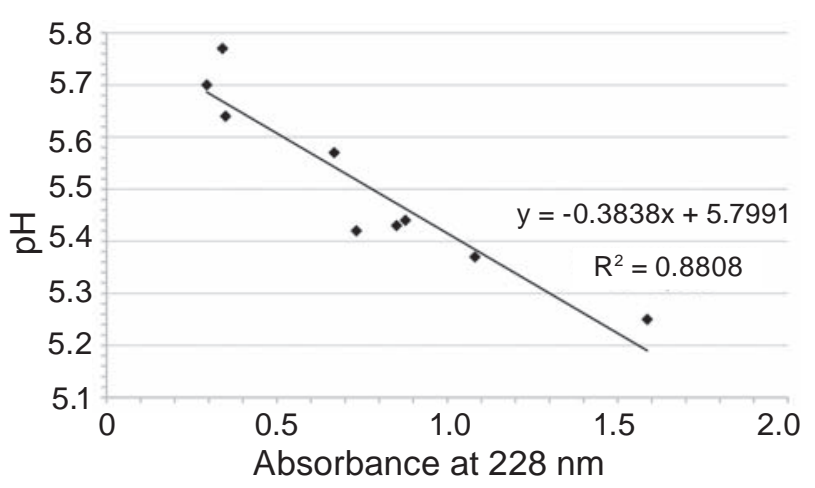

Fig. 3. Dependence of the $\mathrm{pH}$ of tested PD solutions on the absorbance at $228 \mathrm{~nm}$ 


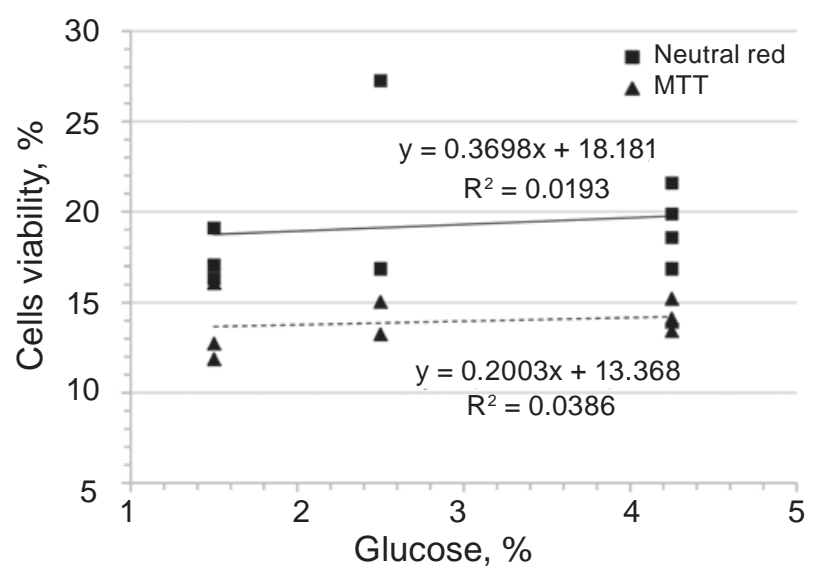

Fig. 4. Comparison of the cell viability for different glucose concentrations of the tested PD solutions

isotonic sodium chloride solution. Our results are in line with data of Erixon et al. [6, 7]. These authors also determined growth inhibition of human peritoneal mesothelium cells and mouse L-929 fibroblast cells by PD solutions using the NR test. However, our studies are not in line with data of these authors concerning correlations because the cell viability even at a weak correlation increases with a $\mathrm{pH}$ decrease, an increase in the absorbance at $228 \mathrm{~nm}$ of the solutions and increase in the sodium lactate concentration in the NR test. One of the drawbacks of the NR absorption assay is its $\mathrm{pH}$ dependence, which, in the case of solutions with different $\mathrm{pHs}$, interferes with establishing an accurate correlation between $\mathrm{pH}$ of these solutions and cell viability. The fact that NR accumulates in lysosomes can also be explained by the increased permeability of living cell membranes in the presence of lower $\mathrm{pH}$ values of the solutions and increased retention of NR inside the lysosomes of living cells at lower $\mathrm{pH}$ of solutions. Our assumption is based on the data of Noh et al. (2006) that ROS generated by conventional PD solutions are, in large part, responsible for peritoneal membrane hyperpermeability, neoangiogenesis, accumulation of extracellular matrix, and eventual peritoneal fibrosis regardless of whether ROS are produced by high glucose, angiotensin II, or GDPs [13]. Therefore, one of the conclusions of our study is that the NR test is not suitable for comparative studies of PD solutions which differ in $\mathrm{pH}$, as it is $\mathrm{pH}$ dependent and does not enable the comparison of plausible cell viability after changes in solution $\mathrm{pH}$ or adjusted manufacturing solutions.

Morphology. According to morphological data, the following changes in Vero line cells were ob-

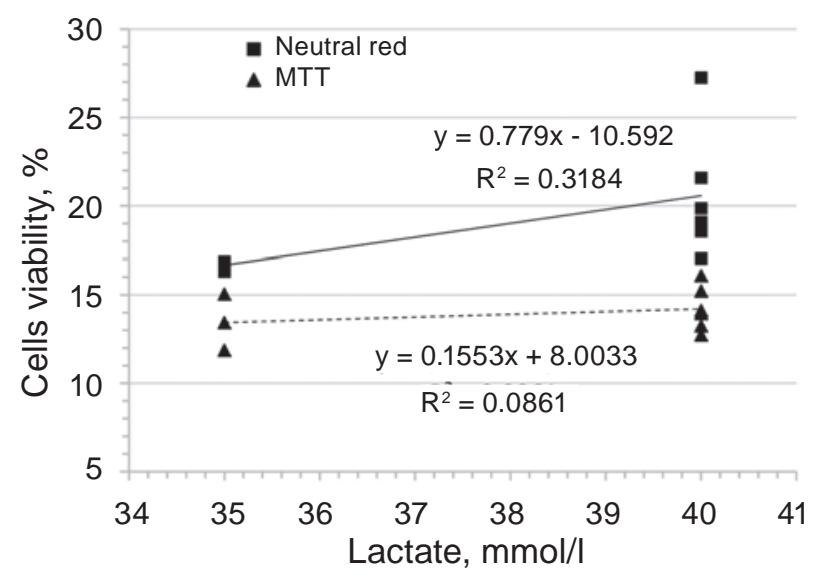

Fig. 5. Comparison of the cell viability for different sodium lactate concentrations

served. In the control wells, in which the tested solutions were not added, strong accumulation of dye was noted, indicating intact cell membranes. The undiluted tested solutions caused damage to the cell monolayer of the membranes. In this case, the dead cells were rounded, colorless, and intercellular contacts were absent. The influence of solution samples with dilutions of $2: 1$ and $1: 1$ was characterized by a sufficiently large number of painted cells. The intensity of coloration of cells after incubation with the tested solutions in the smallest dilution $(2: 1)$ was practically the same as in control wells (Fig. 7). These data are in line with those reported by Andrusev (2005) about breaks in places of intercellular contacts under the influence of PD solutions [14].

Conclusions. Thus, this paper presents approaches to the development or/and changes of the composition and technology PD solutions containing glucose and sodium lactate and evaluation of their cytotoxic activity. The results of this study suggest

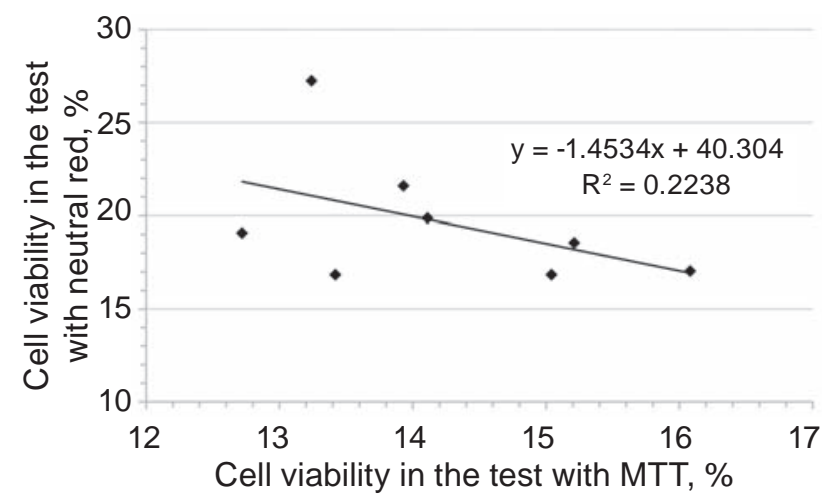

Fig. 6. Correlation of the cell viability in the MTT and NR tests 


\section{Sample 0}
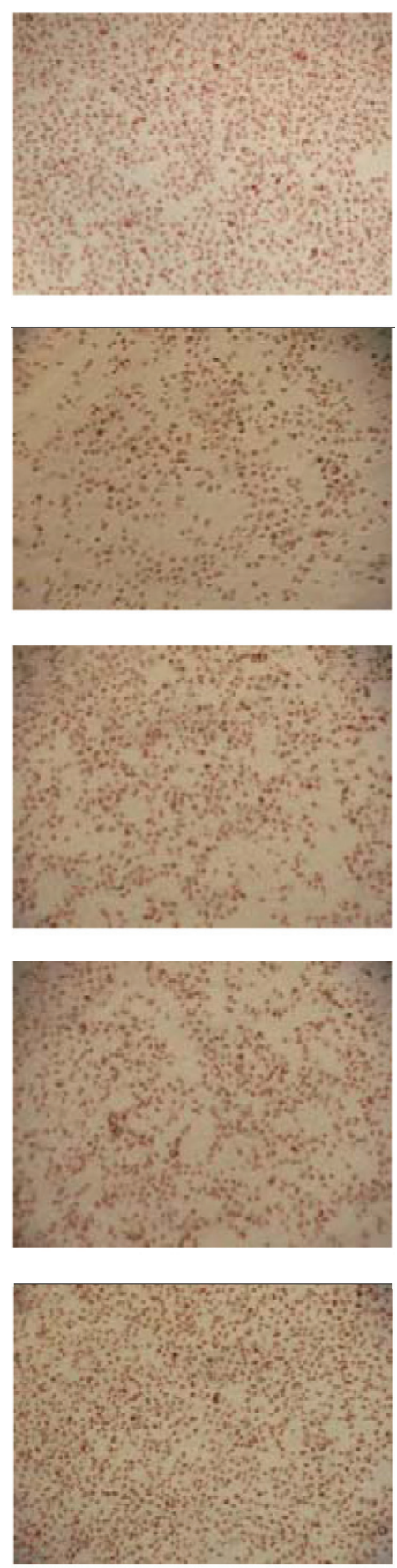

Sample 1(10413)

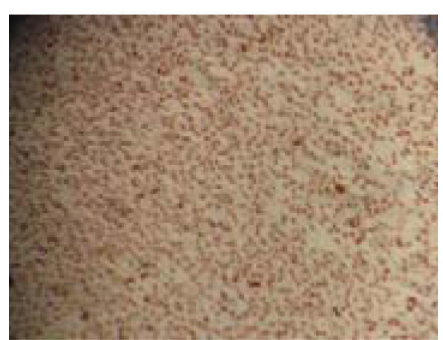

Control

Control

Undiluted

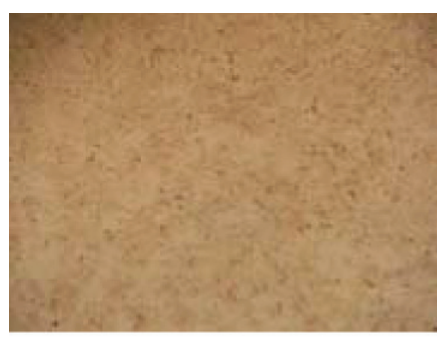

Undiluted

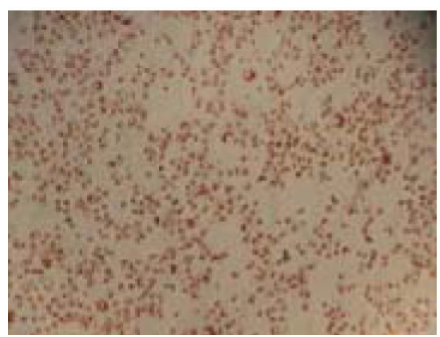

A dilution of $3: 1$

A dilution of $3: 1$

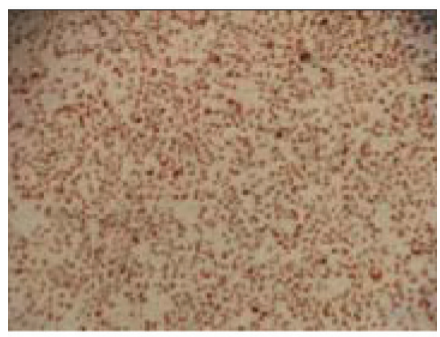

A dilution of $2: 1$

A dilution of $2: 1$

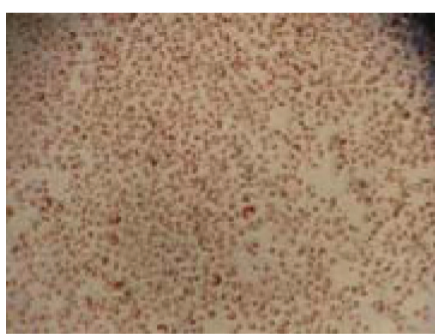

A dilution of $1: 1$

A dilution of $1: 1$

A dilution of 1 :

Fig. 7. Morphological signs of the Vero cells in the presence of the tested solutions and their dilutions in the NR test (the magnification factor is 400)

that the cytotoxic activity of the tested PD solutions and isotonic solution of sodium chloride was greatest when cells were incubated with undiluted PD solutions. When the solutions were diluted by cultivation medium, the amount of viable cells was increased, and at a dilution of $1: 2$ it was close to the values in the control wells where the tested solutions were ab- sent. In the NR test weak, almost middle $(r=-0.496$ and 0.498 , respectively) and unexpected correlations were found between reduced viability of monkey kidney cells and increased $\mathrm{pH}$ of the PD solutions and between increased cell viability and increased absorbance at $228 \mathrm{~nm}$ of the tested PD solutions. These two correlations can be explained by a strong 
correlation ( $r=-0.948)$ between a decrease in $\mathrm{pH}$ and an increase in the solution absorbance at $228 \mathrm{~nm}$. The opposite effects were observed in the MTT test. The weak, but expected correlations $(r=0.32$ and -0.202 , respectively) were found between increased cell viability and increased $\mathrm{pH}$ in the PD solutions and between decreased cell viability and increased absorbance at $228 \mathrm{~nm}$ of the tested PD solutions. The middle and weak correlations ( $r=0.56$ and 0.29 , respectively) were detected between increased cell viability and increased lactate concentration in the NR test and MTT test. The data of these correlations can be partially explained by the fact that a correlation with a coefficient of $r=-0.34$ was found between decreased $\mathrm{pH}$ in the solutions and increased lactate concentration. The very weak correlations $(0.138$ and 0.196 , respectively) were found between increased cell viability and increased glucose concentration in the NR test and MTT test. These experimental data indicate that $\mathrm{pH}$ is the dominating factor, which determines almost all of the established correlations. However, the character of the correlations is quite different: the higher the $\mathrm{pH}$, the greater was the cell viability in the MTT test, and conversely, the higher the $\mathrm{pH}$, the lower was the cell viability in the NR test. Secondly, the unexpected correlation coefficient was determined as -0.473 between decreased cell viability in the MTT test and increased cell viability in the NR test. Moreover, this phenomenon indicates that the mitochondrial enzyme succinate dehydrogenase is more vulnerable to the action of PD solutions than membrane permeability. Finally, we conclude that the NR test is not suitable for comparative studies of PD solutions which differ in $\mathrm{pH}$, as it is $\mathrm{pH}$ dependent and does not enable the comparison of plausible cell viability. Therefore, these research findings serve as a foundation for pharmaceutical development or improving solution composition by $\mathrm{pH}$ elevation or adjusting sterilization processes of PD solutions, and could be useful in the context of planning the authorization and manufacture of PD solutions in cost-conscious countries in order to reduce the burden on health-care resources, including Ukraine. The next stage of our research will focus on comparative studies of our PD solutions with $\mathrm{pH}$ greater than 5.5 to solutions from the main global manufacturers of these solutions.

\section{Acknowledgments}

We thank Cedars-Sinai Medical Center's International Research and Innovation in Medicine Program, the Association for Regional Cooperation in the Fields of Health, Science and Technology (RECOOP HST Association) for their support. Coauthor Nataliia Hudz is grateful to the International Visegrad Fund (contract No. 51700107) for providing the scholarship for studies related to solutions for dialysis therapy.

\section{References}

1. Yu X, Mehrotra R, Yang X. Components of A Successful Peritoneal Dialysis Program. Semin Nephrol. 2017; 37(1): 10-16.

2. Li PK, Kwong VW. Current Challenges and Opportunities in PD. Semin Nephrol. 2017; 37(1): 2-9.

3. Schmitt CP, Aufricht C. Is there such a thing as biocompatible peritoneal dialysis fluid? Pediatr Nephrol. 2017; 32(10): 1835-1843.

4. Saidakova N., Kozlyuk N., Nikolaenko S., Stepanova N. Peritoneal dialysis in Ukraine: 2009-2013. Ukr J Nephrol Dialysis. 2014; (4): 21-30.

5. Cho Y, Johnson DW, Badve SV, Craig JC, Strippoli GF, Wiggins KJ. The impact of neutral$\mathrm{pH}$ peritoneal dialysates with reduced glucose degradation products on clinical outcomes in peritoneal dialysis patients. Kidney Int. 2013; 84(5): 969-979.

6. Erixon M, Lindén T, Kjellstrand P, Carlsson O, Ernebrant M, Forsbäck G, Wieslander A, Jönsson JA. PD fluids contain high concentrations of cytotoxic GDPs directly after sterilization. Perit Dial Int. 2004; 24(4): 392-398.

7. Erixon M, Wieslander A, Lindén T, Carlsson O, Forsbäck G, Svensson E, Jönsson JA, Kjellstrand P. Take care in how you store your PD fluids: actual temperature determines the balance between reactive and non-reactive GDPs. Perit Dial Int. 2005; 25(6): 583-590.

8. Diaz-Buxo JA, Sawin DA, Himmele R. PD solutions: new and old. Dial Transplant. 2011; 40(8): 356-363. 
9. Hanrahan CT, Himmele R, Diaz-Buxo JA. The challenges of heat sterilization of peritoneal dialysis solutions: is there an alternative? Adv Perit Dial. 2012; 28: 126-130.

10. Hudz N. I. Spectrophotometric analysis in the development of peritoneal dialysis solutions. Vestnik Pharmacii. 2015; 70(4): 63-70. (In Russian).

11. Haybrard J, Simon N, Danel C, Pinçon C, Barthélémy C, Tessier FJ, Décaudin B, Boulanger E, Odou P. Factors generating gucose degradation products in sterile glucose slutions for infusion: statistical relevance determination of their impacts. Sci Rep. 2017; 7(1): 11932.

12. British Pharmacopoeia. Edition 2009, Publisher London: The Stationery Office: 2009, 10952 p.

13. Noh H, Kim JS, Han KH, Lee GT, Song JS, Chung SH, Jeon JS, Ha H, Lee HB. Oxidative stress during peritoneal dialysis: implications in functional and structural changes in the membrane. Kidney Int. 2006; 69(11): 2022-2028.

14. Andrusev AM. Peritoneal dialysis: longterm results, their determinants, and clinical pathophysiology. Nephrol Dialysis. 2005; 7(2): 110-129. (In Russian).

15. Distler L, Georgieva A, Kenkel I, Huppert J, Pischetsrieder M. Structure- and concentrationspecific assessment of the physiological reactivity of $\alpha$-dicarbonyl glucose degradation products in peritoneal dialysis fluids. Chem Res Toxicol. 2014; 27(8): 1421-1430.

16. Florento L, Matias R, Tuaño E, Santiago K, Dela Cruz F, Tuazon A. Comparison of cytotoxic activity of anticancer drugs against various human tumor cell lines using in vitro cell-based approach. Int J Biomed Sci. 2012; 8(1): 76-80.

17. Repetto G, del Peso A, Zurita JL. Neutral red uptake assay for the estimation of cell viability/ cytotoxicity. Nat Protoc. 2008; 3(7): 1125-11231.

18. Hudz N, Filipska A. Elements of standardization and quality control of laboratory batches of peritoneal dialysis solutions containing dextrose and sodium lactate. ScienceRise: Pharmaceutical Sci. 2017; (1): 4-12. (In Ukrainian).

19. Achim Bühl, Peter Zöfel. SPSS Version 10. Einführung in die modern Datenanalyse unter Windows, 7, überarbeitete und erweiterte Auflage, Diasoft: 2005, 602 p. (In Russian).

20. Kjellstrand P, Erixon M, Wieslander A, Lindén T, Martinson E. Temperature: the single most important factor for degradation of glucose fluids during storage. Perit Dial Int. 2004; 24(4): 385-391.

Received 22.03.2018 